\title{
Toward to Measure Narcissistic Personality in Cyberspace: Validity and Reliability
}

\author{
Chih-Hung Chou, C. K. Farn \\ Department of Information Management, National Central University, Taiwan \\ Email: gtcch@hotmail.com
}

Received 23 October 2015; accepted 4 December 2015; published 7 December 2015

Copyright (C) 2015 by authors and Scientific Research Publishing Inc.

This work is licensed under the Creative Commons Attribution International License (CC BY). http://creativecommons.org/licenses/by/4.0/

c) (†) Open Access

\begin{abstract}
Behavior in Internet world is closely related to narcissistic personality. Internet is a necessary part of life for young: therefore, the discussion of narcissistic behavior and the implicit personality traits within Internet world has become an important issue for understanding the psychology and behavior of teenagers. Currently, well-developed narcissistic personality scales exist for academic use; however, the plausibility of applying them in Internet world still lacks systematic proof. Thus, our study developed a narcissistic personality scale focused on online behavior based on college students sampled in Taiwan, and tested the construct validity of the scale through confirmatory factor analysis. The results show that the Online Narcissistic Personality Inventory (ONPI) developed in our study is composed of seven facets and that all facets have good internal consistency; factor analysis of the seven-factor model shows good model fit. The results show that the ONPI can be applied for assessing narcissistic personality in online environments for college students.
\end{abstract}

\section{Keywords}

Online Narcissistic Scale, Reliability, Validity

\section{Introduction}

During the past ten years, many articles have shown information technology usage to be closely related to personality traits. One of the personality traits that have recently gathered attention is narcissism (Carpenter, 2012; Ong et al., 2011). Perhaps the most typical manifestation of narcissistic behavior through smart phone and social networks sites is the selfie. On the other hand, selfie behavior is closely related to cyberspace narcissism personality, which has been brought about by social network sites (Twenge \& Campbell, 2009). In Internet world, when people are online, they can fulfill their emotional needs of narcissistic personality by pouring attention into and updating their web pages on social networks or by interacting with others online. 
Past studies related to narcissism and the Internet mostly focused on the correlation between people's narcissism in the real world and their behavior on the Internet. Buffardi \& Campbell (2008) show that the individuals having higher scores on a narcissistic personality scale often have more interactions with others on Facebook, and that researchers can predict the degree of narcissism of a user simply from the content of their Facebook pages. Panek et al. (2013) discover that narcissists enjoy social networks such as Facebook and Twitter and like to use them to express narcissistic behavior. However, narcissistic behaviors on the Internet are different from those from real world in many aspects (e.g. narcissistic surfing). Currently, academic circles possess a well-developed narcissistic personality scale, and have applied it to detect connections between narcissistic personality traits and behavior on the Internet; nevertheless, a narcissistic personality assessment scale designed for cyberspace behavior in particular is still missing. Therefore, it is necessary to establish a narcissistic personality scale specialized for cyberspace to reflect the narcissism of individuals on the Internet.

\section{Literature Review}

\subsection{E-Personality}

In Internet world, personality may not appear the same as in real life because the environment is likewise different from real life. Wallace (2001) denoted "online persona" differs with the real-life personas as we show in different occasions meeting different persons. While desires for certain reckless behavior is "hidden" in an individual's mind normally, and not expressed in the real world, it is nonetheless a part of his or her personality and finds release over the Internet (Suler, 2004). Walther (1996) introduced the concept of hyperpersonal communication, saying that the interaction experience provided by a computer acting as a communication intermediary is more attractive than face-to-face communication, because selectivity and the ability of individuals to gaina positive impression is improved in this kind of environment. Reduced cues and permissibility of asynchronous communication allow the Internet user to achieve more efficient selective self-presentation. Because the Internet offers the opportunity for people to present themselves in different ways, coupled with the inherent features of anonymity, physical distance, and deindividuation, Internet users have enough space to pursue various kinds of identity transformation and self-exploration (Turkle, 1995). The concept of the "E-personality" makes individuals calibrate their offline lives, and thus behavior from their Internet personality may affect their off-line personality as well (Aboujaoude, 2012).

\subsection{Online Narcissistic Personality and Behavior}

Narcissism is characterized as a tendency to consider one's self to be better than others, to constantly seek veneration from others, and to engage in self-centered thinking and behavior (Campbell et al., 2002; Morf \& Rhodewalt, 2001). Narcissistic personality is also defined as a personality lacking empathy, unable and unwilling to accept love from others, centered on oneself, and exaggerating one's own importance. Healthy levels of narcissism can help develop self-affirmation (Stolorow, 1975) but excessive narcissism is clinically diagnosed as an abnormal personality, called Narcissistic Personality Disorder (NPD). Narcissistic personality is thus more accurately a disease spectrum, and everyone has this characteristic to varying degrees. Accordingly, Raskin \& Hall (1981) developed the 54-item Narcissistic Personality Inventory (NPI) to assess narcissistic tendencies in the general population. Then, Raskin \& Terry (1988) subdivided the single NPD perspective into seven facets, including Authority, vanity and entitlement. A higher score indicates a higher tendency of narcissism in each of the seven subscales.

Twenge et al. (2008) tested over 30 thousand American college students and discovered that narcissistic personality is common in the young population. Because young people form a major subpopulation of Internet users, understanding the effect of Internet use on narcissistic personality development is a rather important issue. For example, narcissism predicted reasons why Millennials use social network sites (SNSs), such as having as many SNSs friends as possible, wanting their SNS friends to know what they were doing, believing their SNS friends were interested in what they are doing, and having their SNS profiles project a positive image. Findings suggest that Millennials' general usage of SNSs is a sign of the times (Bergman et al., 2011). An investigation into 1471 online game players found narcissistic personality to be positively correlated with online gaming addiction (Kim et al., 2008), indicating that narcissists can easily find elements or characters in online games that fulfill their narcissism needs and unconsciously indulge in them. More than ever, information technology aims 
to satisfy users' every need and put them in the driver's seat that make users more I-center. Internet may give the user opportunity to turn himself into a better one and to show off even more. SNSs become very effective outlets of self-promotion. Aboujaoude (2012) argued that narcissism a personality trait that can be nurtured by the Wed and that marks many people's E-personality. These studies confirm that narcissism is a very important feature of E-personality, and that we accordingly need a proper scale to measure it.

\subsection{The Measure of Online Narcissistic Personality}

Toward a measure of online narcissistic personality, our study argue that individuals in an internet environment act differently from in the real world, and their personality presented online may differ from their social, real-life personality. On the other hand, behavioral patterns on the internet are different from in the real world and thus the personality characteristics reflected by the behavior are also different. Accordingly, the assessment tool should be different: a scale designed specifically for Internet behavior can present actual Internet behavior without causing any confusion with real world behavior. Thus, our study is focused on designing an Online Narcissistic Personality Inventory (ONPI) in an attempt to provide a tool to faithfully reflect narcissism behavior on the Internet to be applied to subjects for future research. Our study defined online narcissistic personality as "for an individual in an Internet environment, an authoritative personality, confident of handling anything, thinking himself superior to others, showing strong exhibitionism, in favor of manipulating and take advantage of others to acquire personal gain, fulfilled by vanity, and seeking entitlement”. Our adoption and validity procedure of the ONPI mostly followed the procedure proposed by De Vellis (2003) and Mac Kenzie et al. (2011). Since the subpopulation in Taiwan that uses the Internet most frequently is college students, our study collected college students from four colleges of different types in Taiwan in order to test the validity and reliability of the ONPI.

\section{Methods}

\subsection{Process and Participants}

Our study took undergraduate students as research subjects from colleges in Taiwan, including national central university, Chi Nan University, National University of Kaohsiung and National Kaohsiung University of Applied Sciences. For each university, we selected a full-time teacher employed by the university and invited the students within his or her class to fill out the ONPI for a 50 NTD gift card as a reward. Informed consent was signed by all the participants prior to data collection. In total, we sent out 576 questionnaires; after subtracting invalid samples, we obtained 471valid samples having an age distribution mainly between 19 to 24 years old. The gander of valid samples includes 221 women (46.9\%), 248 men (52.7\%) and 2 subjects (.4\%) whose sex is unknown.

We first performed a pilot test before formally distributing the questionnaire in order to discover if there were questions that might be misunderstood due to ambiguous wording and avoid their interference on scale validity. We gave out 92 questionnaires during the pilot test to students of the employer of the current study's first author, and 76 valid questionnaires were returned. During the pilot test, if subjects had any concerns or problems when answering, they could either mention them through a comment section at the end of the questionnaire or communicate with the researchers administering the questionnaire on the spot. According to the suggestions and feedback from the subjects of the pilot test, we performed final adjustments on the scale during a weekly meeting among the study authors and built the final version of the ONPI.

\subsection{Instrument}

The NPI-40 (Narcissistic Personality Inventory) developed by Raskin and Terry (1988) is the most widely used narcissistic personality scale academically and in practice. Our study adopted the NPI-40 scale as the basis for constructing the ONPI. NPI-40 has 40 items in total, measuring seven narcissistic personality facets: authority (the degree to which an individual feels he/she can influence others in Internet world, e.g. "I have a natural talent for influencing people in the Internet world"); self-sufficiency (the degree to which an individual feels he/she can fully control a situation and independently make decisions and support himself in Internet world, e.g. "I always know what I am doing in the Internet world"); superiority (the degree to which an individual feels he/she is more brilliant than others in Internet world, e.g. "I am an extraordinary person in the Internet world"); exhibitionism (the tendency of an individual to exhibit him/herself and put him/herself in the spotlight in Inter- 
net world, e.g. "I dare to do almost anything in the Internet world”); exploitativeness (the tendency of an individual to manipulate or take advantage of others in Internet world, e.g. "I find it easy to manipulate others in the Internet world"); vanity (the degree to which an individual feels he/she is confident in his/her abilities or is attractive to others in Internet world, e.g. "I am fond of displaying my photos in the Internet world"); entitlement (the degree to which an individual thinks he/she deserves some kind of reward or benefit in Internet world, e.g. "If I were the ruler of the Internet, it would be much better for the Internet community). The scale items were all Likert-scale items and item score was calculated from 1 (=“strongly disagree”) to 5 (=“strongly agree”). The total summed score for all items within each facet was the facet score; higher score indicated stronger features of that facet.

The initial items of the scale were discussed by a professor, three PhD students, three professionals from the industry community, and three graduate students during weekly meetings. We intended to change neither the number of items from the NPI-40 nor the implication of the original items, and focused on changing the items originally regarding behaviors in real-world social environments to behaviors in Internet world environments. The discussion was divided into two stages. At the first stage, we checked whether each scale item could be directly applicable in Internet world. If the item would not be manifested in Internet world or it was uncertain if it would be applicable in its intended sense, then we continued to the second stage. At the second stage, the researchers consulted and discussed with related professionals and further during weekly meetings regarding the controversial items from the first stage, aiming to make each item description capable of capturing the behavior of an individual in Internet world in a reasonable way. After finishing the development of the initial scale, we asked English professionals to perform translation and back-translation. After bidirectional translation, we invited five professionals with practical experience and scholars to join the item development and interviewed them to assure their professional credentials. We required the invited subjects to have more than ten years of related research experience for scholars or of related practical working experience for professionals (e.g., social network-related experience, roles as forum moderators, bloggers, Facebook fan club managers, etc.). After the interviews, we adjusted the content of initial items with reference to the opinion of the interviewees, after which we performed the pilot test with the adjusted version and further adjusted the scale, as showed in appendix 1.

\subsection{Statistical Analysis}

Our study used SPSS to perform statistical analysis and used LISREL to perform confirmatory factor analysis to test the construct validity of the scale. The internal consistency of narcissism and facets were assessed by Cronbach's $\alpha$. Hair et al. (1998) suggested that Cronbach's $\alpha$ must be at least .6 and greater than .9 to confirm a scale to have good reliability. In terms of validity, our study used construct validity to test the ONPI. Construct validity represents the degree that a scale can truly reflect the construct or personality features it intends to measure; it is usually tested using confirmatory factor analysis.

Our study performed model fit analysis through structural equation modeling (SEM), which was based on the seven facets of the NPI-40. In terms of fit index of model fit, our study referred to the opinions of Bagozzi and Yi (1988), Jöreskog and Sörbom (1989), and Hair et al. (1998), and chose the ratio of $\chi^{2}$ and degrees of freedom $\left(\chi^{2} /\right.$ d.f.), GFI, AGFI, NFI, NNFI, CFI, and RMSEA as the seven indexes for assessment. Specifically, $\chi^{2} /$ d.f. must not be larger than 5; GFI, NFI, NNFI, and CFI should be larger than .9; AGFI should be larger than .8; and RMSEA should be lower than .08 .

\section{Results}

\subsection{Statistics and Reliability}

The 40 items of the ONPI developed in our study have fairly good overall internal consistency $(\alpha=.963)$. Table 1 shows the reliability of each personality facet, also showing satisfactory internal consistency with $\alpha$-values. These results indicate that ONPI in our study has satisfactory reliability.

\subsection{Measurement Model}

The measurement model was first evaluated in terms of reliability, convergent validity, and discriminant validity. Reliability in SEM was examined using the compose reliability values. As shown in Table 1, all were above .7; this indicates a commonly acceptable level for explanatory research. Convergent validity was evaluated for the 
Table 1. Mean and standard deviation for each item and Cronbach's $\alpha$ of facets in the ONPI.

\begin{tabular}{|c|c|c|c|c|c|c|c|c|}
\hline Narcissism facet & Item & Number & Mean & S.D. & Factor loading & Cronbach's alpha & CR & AVE \\
\hline \multirow{8}{*}{ Authority } & Aut1 & 01. & 3.13 & .798 & .80 & \multirow{8}{*}{.93} & \multirow{8}{*}{.95} & \multirow{8}{*}{.71} \\
\hline & Aut2 & 08. & 3.22 & .801 & .83 & & & \\
\hline & Aut3 & 10. & 3.11 & .829 & .88 & & & \\
\hline & Aut4 & 11. & 3.30 & .905 & .81 & & & \\
\hline & Aut5 & 12. & 2.96 & .892 & .79 & & & \\
\hline & Aut6 & 32. & 2.90 & .776 & .86 & & & \\
\hline & Aut7 & 33. & 2.96 & .886 & .89 & & & \\
\hline & Aut8 & 36. & 2.83 & .849 & .88 & & & \\
\hline \multirow{6}{*}{ Self-Sufficiency } & Sel1 & 17. & 3.23 & .843 & .82 & \multirow{7}{*}{.89} & \multirow{7}{*}{.90} & \multirow{6}{*}{.61} \\
\hline & Sel2 & 21. & 3.42 & .779 & .72 & & & \\
\hline & Sel3 & 22. & 3.35 & .769 & .68 & & & \\
\hline & Sel4 & 31. & 3.35 & .811 & .72 & & & \\
\hline & Sel5 & 34. & 3.09 & .838 & .88 & & & \\
\hline & Sel6 & 39. & 3.13 & .767 & .84 & & & \\
\hline \multirow{5}{*}{ Superiority } & Sup1 & 04. & 2.82 & .836 & .78 & & & \multirow{5}{*}{.63} \\
\hline & Sup2 & 09. & 3.29 & .855 & .80 & \multirow{4}{*}{.87} & \multirow{4}{*}{.90} & \\
\hline & Sup3 & 26. & 2.96 & .888 & .79 & & & \\
\hline & Sup4 & 37. & 2.88 & .986 & .80 & & & \\
\hline & Sup5 & 40. & 3.06 & .853 & .80 & & & \\
\hline \multirow{7}{*}{ Exhibitionism } & Exh1 & 02. & 2.81 & .877 & .74 & \multirow{7}{*}{.91} & \multirow{7}{*}{.93} & \multirow{7}{*}{.65} \\
\hline & Exh2 & 03. & 2.76 & .925 & .78 & & & \\
\hline & Exh3 & 07. & 2.78 & .924 & .87 & & & \\
\hline & Exh4 & 20. & 3.03 & .832 & .83 & & & \\
\hline & Exh5 & 28. & 2.93 & .898 & .82 & & & \\
\hline & Exh6 & 30. & 2.86 & .911 & .82 & & & \\
\hline & Exh7 & 38. & 2.80 & .909 & .76 & & & \\
\hline \multirow{5}{*}{ Exploitativeness } & Exp1 & 06. & 2.86 & .979 & .85 & \multirow{5}{*}{.86} & \multirow{5}{*}{.90} & \multirow{5}{*}{.64} \\
\hline & Exp2 & 13. & 2.83 & .944 & .85 & & & \\
\hline & Exp3 & 16. & 3.10 & .902 & .81 & & & \\
\hline & Exp4 & 23. & 2.95 & .701 & .73 & & & \\
\hline & Exp5 & 35. & 3.08 & .817 & .76 & & & \\
\hline \multirow{3}{*}{ Vanity } & Van1 & 15. & 2.89 & 1.053 & .90 & \multirow{3}{*}{.88} & \multirow{3}{*}{.91} & \multirow{3}{*}{.76} \\
\hline & Van2 & 19. & 2.97 & 1.022 & .84 & & & \\
\hline & Van3 & 29. & 3.00 & 1.003 & .88 & & & \\
\hline & Ent1 & 05. & 3.15 & 1.010 & .77 & & & \\
\hline & Ent2 & 14. & 3.42 & .787 & .78 & & & \\
\hline Entitlement & Ent3 & 18. & 3.35 & .850 & .81 & 87 & 90 & 61 \\
\hline Бाराप & Ent4 & 24. & 3.39 & .858 & .77 & .07 & .0 & .01 \\
\hline & Ent5 & 25. & 3.12 & .836 & .76 & & & \\
\hline & Ent6 & 27. & 3.01 & .969 & .79 & & & \\
\hline
\end{tabular}

measurement scales using two criteria suggested by Fornell and Larcker (1981): 1) all indicator factor loadings should be significant and exceed .70 and 2 ) average variance extracted (AVE) for each construct should exceed 
the variance due to measurement error for that construct (i.e., should exceed .50). As shown in Table 1, items exhibited loading higher than .7 on their respective facets, providing evidence of acceptable item convergence on the intended constructs. AVE ranged from .61 to .76 (see Table 2), greater than variance due to measurement error. Hence, all two conditions for convergent validity were met.

For satisfactory discriminant validity, the square root of the AVE from the construct should be greater than the correlation shared between the construct and other constructs in the model (Fornell \& Larcker, 1981). Table 2 lists the correlations among constructs, with the square root of the AVE on the diagonal. The diagonal values exceed the inter-construct correlations; hence the test of discriminant validity was acceptable. Therefore we conclude that the measure for each construct satisfies construct validity.

\subsection{Structural Model}

The scale was tested using LISREL 9.1. Using sample covariance matrices, the overall fit was examined, together with the relative strengths of the individual causal path. Within the structural model for ONPI in our study (Figure 1), the standardized regression coefficients were all significant, implying that the model of online narcissistic personality with seven facets is quite stable. From Table 3, we can see that the fit indexes of the models of our study nearly all reached their standard ideal values, with only GFI slightly lower than its ideal value, indicating that the model of our study had good model fit.

\section{Discussion}

Most past studies, lacking measurement instruments customized to online environments, have used general narcissistic personality inventories instead, meaning researchers cannot detect meaningful differences between narcissistic personality facets manifested in Internet world versus in the real world. Our study modified the ONPI based on the NPI-40, attempting to properly assess the narcissistic personality of online users and understand

Table 2. Correlations and AVE.

\begin{tabular}{|c|c|c|c|c|c|c|c|}
\hline Facet & Authority & Self-Sufficiency & Sup & Exhibitionism & Exploitativeness & Vanity & Entitlement \\
\hline Authority & .84 & & & & & & \\
\hline Self-Sufficiency & .74 & .78 & & & & & \\
\hline Superiority & .77 & .66 & .79 & & & & \\
\hline Exhibitionism & .75 & .61 & .80 & .81 & & & \\
\hline Exploitativeness & .75 & .64 & .69 & .73 & .80 & & \\
\hline Vanity & .43 & .35 & .47 & .58 & .40 & .87 & \\
\hline Entitlement & .64 & .54 & .61 & .66 & .56 & .45 & .78 \\
\hline
\end{tabular}

Notes: Diagonal elements (in bold) represent the square root of the average variance extracted (AVE). Off-diagonalelements represent the correlations among constructs.

Table 3. CFA fit indices for ONPI.

\begin{tabular}{cccc}
\hline Fit indices & Scholars & Recommended value & ONPI value \\
\hline$\chi^{2} / \mathrm{df}$ & Bollen (1989) & $\leq 3.0$ & 2.65 \\
GFI & Scott (1994) & $\geq .9$ & .84 \\
AGFI & Scott(1994) & $\geq .8$ & .81 \\
NFI & Bentler \& Bonett (1980) & $\geq .9$ & .98 \\
NNFI & Bentler \& Bonett (1980) & $\geq .9$ & .98 \\
CFI & Bagozzi \& Yi (1988) & $\geq .9$ & .98 \\
RMSEA & MacCallum (1996) & $\leq .08$ & .059 \\
\hline
\end{tabular}




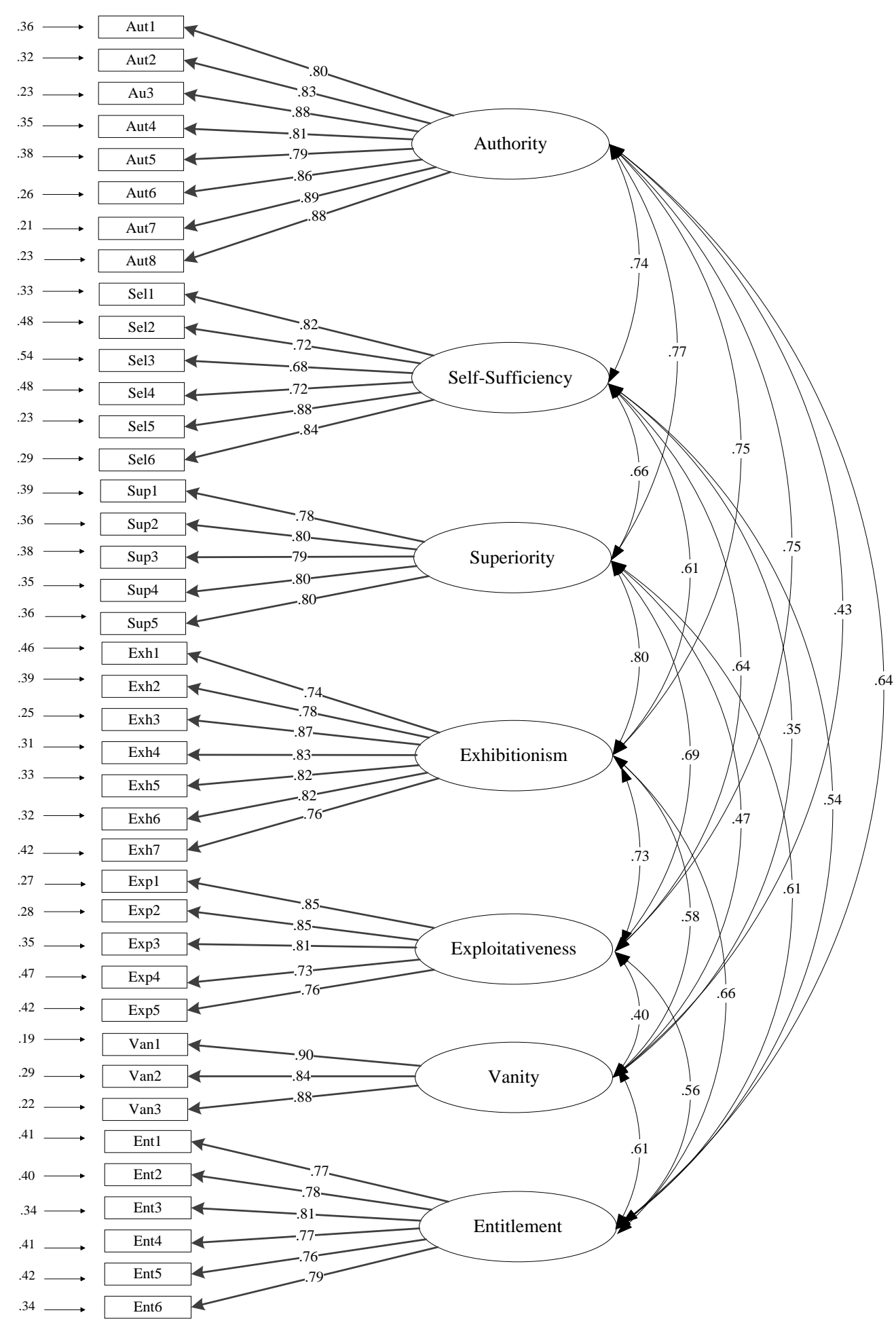

Figure 1. The measurement model of online narcissistic personality inventory.

narcissistic behavior in the online setting. The results showed the ONPI to possess fairly good reliability and validity. Similar to the real-life narcissistic personality construct as captured by the NPI-40, online narcissistic personality has multiple dimensions, thus it is reasonable to explain online narcissistic personality in terms of the isolated constructs. 


\subsection{Findings}

The ONPI developed in our study based on NPI-40 possesses fairly good reliability and validity, not only implying that ONPI is a valid tool for assessing Internet narcissistic personality, but also that the narcissistic behavior of college students as manifested online may not be so different from real life. The confirmatory factor analyses of ONPI show that Internet narcissistic personality has seven constructs, the same as for NPI-40, and that these seven constructs mostly align to the seven facets of the NPI-40. Although some articles have emphasized that individuals may exhibit different behaviors on the Internet versus in the real world (Aboujaoude, 2012; Suler, 2004), the lives of college students are perhaps simpler than those of the general population, and so any differences present between the two environments may not be distinguishable because of the limited subject variation present. For example, adults who would otherwise freely share selfie pictures on the Internet may be concerned about their official image or identity and avoid taking selfies in many occasions in the real world, whereas taking selfies is an accepted and popular behavior in college populations: therefore, the former may show significant differences between their NPI-40 and ONPI results, but the latter may not. We recommend that future studies choose different populations, perform assessment with both tools, and compare differences to evaluate the possibility of the above supposition being true. Moreover, the results of our study may be caused by unique constructs to Internet narcissistic personality not present in real world narcissistic personality, which can be captured by neither the facets of the ONPI nor those of the NPI-40. If individuals perform such special, heretofore unidentified behaviors in Internet world, neither the NPI-40 nor the ONPI will reflect these behaviors since the latter is developed from the former. Our study possessed validity 471 undergraduate students from different types of university and different areas of Taiwan. The result revealed the situation of narcissism personality traits of college students in Taiwan. It is strongly suggesting that narcissistic personality becomes more and more explicitly nowadays. We must pay more attention to this issue. Our study can be used robustly as a reference for practical and academic purpose.

\subsection{Implications}

Some scholars believe that Narcissism is a manifestation of a child not progressing from self-love phase to the object-love phase. Nowadays, individuals come into contact with and use Internet and smart phones during childhood, and interaction with these information technologies is inherently self-oriented, making it easy for an individual to be excessively self-centered and develop excessive narcissism and unhealthy personality traits during maturation, which can further worsen into trends of exaggeration, complacency, conceit, ego, and selfishness, effects that may easily expand into real-world settings (Moeller et al., 2009). For parents and educational professionals, it is very important to understand the online behavior of children and prevent them from being self-centered or developing abnormal narcissism. Specific approaches include supporting a child's selfimage, clarifying the difference between the Internet world and the real world, further regulating the use of social networks, properly supervising the online behavior of the child, and building healthy social connections and routines for the child, efforts that would be greatly helpful for the healthy personality development of coming generations. In addition, appeals to narcissism have become an important business development: sales approaches that take advantage of online narcissistic behavior are just beginning to unfold, and efforts to prevent cybercrime and irrational consumption behavior, such as impulse purchasing behavior on the Internet can start from assessing narcissistic personality traits of individuals. The ONPI developed in our study has good psychometric properties, and it can be used as an instrument to screen for online narcissistic personality in the population.

\subsection{Limitations}

There are several limitations of our study. First, the ONPI is designed based on the NPI-40 narcissistic personality scale, and as such, it may not be able to fully reflect all unique features of online narcissistic personality. Second, due to limitations of cost and manpower, our study chooses college students as research subjects; although it is now very common for college students to use Internet, we still need to consider that our results may not be generalizable to the general population.

\section{References}

Aboujaoude, E. (2012). Virtually You: The Dangerous Powers of the E-personality. New York City, NY: WW Norton \& Company. 
Bagozzi, R. P., \& Yi, Y. (1988). On the Evaluation of Structural Equation Models. Journal of the Academy of Marketing Science, 16, 74-94. http://dx.doi.org/10.1007/BF02723327

Bentler, P. M., \& Bonett, D. G. (1980). Significance Tests and Goodness of Fit in the Analysis of Covariance Structures. Psychological Bulletin, 88, 588-606. http://dx.doi.org/10.1037/0033-2909.88.3.588

Bergman, S. M., Fearrington, M. E., Davenport, S. W., \& Bergman, J. Z. (2011). Millennials, Narcissism, and Social Networking: What Narcissists Do on Social Networking Sites and Why. Personality and Individual Differences, 50, $706-711$. http://dx.doi.org/10.1016/j.paid.2010.12.022

Bollen K. A. (1989). Structural Equations with Latent Variables. New York: Wiley. http://dx.doi.org/10.1002/9781118619179

Buffardi, L. E., \& Campbell, W. K. (2008). Narcissism and Social Networking Web Sites. Personality and Social Psychology Bulletin, 34, 1303-1314. http://dx.doi.org/10.1177/0146167208320061

Campbell, W. K., Rudich, E., \& Sedikides, C. (2002). Narcissism, Self-Esteem, and The Positivity of Self-Views: Two Portraits of Self-Love. Personality and Social Psychology Bulletin, 28, 358-368.

http://dx.doi.org/10.1177/0146167202286007

Carpenter, C. J. (2012). Narcissism on Facebook: Self-Promotional and Anti-Social Behavior. Personality and Individual Differences, 52, 482-486. http://dx.doi.org/10.1016/j.paid.2011.11.011

De Vellis, R. F. (2003). Scale Development: Theory and Applications (2nd ed., Vol. 26). Thousand Oaks, CA: Sage Publications.

Hair, J. F. J., Anderson, R. E., Tatham, R. L., \& Black, W. C. (1998). Multivariate Data Analysis. Upper Saddle River, NJ: Prentice-Hall.

Jöreskog, K. G., \& Sörbom, D. (1989). LISREL 7: A Guide to the Program and Applications. Chicago, IL: SPSS.

Kim, E. J., Namkoong, K., Ku, T., \& Kim, S. J. (2008). The Relationship between Online Game Addiction and Aggression, Self-Control and Narcissistic Personality Traits. European Psychiatry, 23, 212-218. http://dx.doi.org/10.1016/j.eurpsy.2007.10.010

Mac Kenzie, S. B., Podsakoff, P. M., \& Podsakoff, N. P. (2011). Construct Measurement and Validation Procedures in MIS and Behavioral Research: Integrating New and Existing Techniques. MIS Quarterly, 35, 293-334.

MacCallum, R. C., Browne, M. W., \& Sugawara, H. M. (1996). Power Analysis and Determination of Sample Size for Covariance Structure Modeling. Psychological Methods, 1, 130-149. http://dx.doi.org/10.1037/1082-989X.1.2.130

Moeller, S. J., Crocker, J., \& Bushman, B. J. (2009). Creating Hostility and Conflict: Effects of Entitlement and Self-Image Goals. Journal of Experimental Social Psychology, 45, 448-452. http://dx.doi.org/10.1016/j.jesp.2008.11.005

Morf, C. C., \& Rhodewalt, F. (2001). Unraveling the Paradoxes of Narcissism: A Dynamic Self-Regulatory Processing Model. Psychological Inquiry, 12, 177-196. http://dx.doi.org/10.1207/S15327965PLI1204_1

Ong, E. Y. L., Ang, R. P., Ho, J. C. M., Lim, J. C. Y., Goh, D. H., Lee, C. S., \& Chua, A. Y. K. (2011). Narcissism, Extraversion and Adolescents' Self-Presentation on Facebook. Personality and Individual Differences, 50, 180-185. http://dx.doi.org/10.1016/j.paid.2010.09.022

Panek, E. T., Nardis, Y., \& Konrath, S. (2013). Mirror or Megaphone? How Relationships between Narcissism and Social Networking Site Use Differ on Facebook and Twitter. Computers in Human Behavior, 29, 2004-2012. http://dx.doi.org/10.1016/j.chb.2013.04.012

Raskin, R., \& Hall, C. S. (1981). The Narcissistic Personality Inventory: Alternative form Reliability and Further Evidence of Construct Validity. Journal of Personality Assessment, 45, 159-162. http://dx.doi.org/10.1207/s15327752jpa4502 10

Raskin, R., \& Terry, H. (1988). A Principal-Components Analysis of the Narcissistic Personality Inventory and Further Evidence of Its Construct Validity. Journal of Personality and Social Psychology, 54, 890-902. http://dx.doi.org/10.1037/0022-3514.54.5.890

Scott (1994). The Measurement of Information System Effectiveness: Evaluating a Measuring Instrument. Proceedings of the Fifteenth International Conference on Information System, Vancouver, 14-17 December 1994, 111-128.

Stolorow, R. D. (1975). Toward a Functional Definition of Narcissism. International Journal of Psychoanalysis, 56, 179185.

Suler, J. (2004). The Online Disinhibition Effect. Cyberpsychology \& Behavior, 7, 321-326. http://dx.doi.org/10.1089/1094931041291295

Turkle, S. (1995). Life on the Screen: Identity in the Age of the Internet. New York: Simon and Schuster.

Twenge, J. M., \& Campbell, W. K. (2009). The Narcissism Epidemic: Living in the Age of Entitlement. New York: Simon and Schuster. 
Twenge, J., Konrath, S., Foster, J., Campbell, W., \& Bushman, B. (2008). Further Evidence of an Increase in Narcissism among College Students. Journal of Personality, 76, 919-928. http://dx.doi.org/10.1111/j.1467-6494.2008.00509.x

Wallace, P. (2001). The Psychology of the Internet. Cambridge: Cambridge University Press.

Walther, J. B. (1996). Computer-Mediated Communication Impersonal, Interpersonal, and Hyperpersonal Interaction. Communication Research, 23, 3-43. http://dx.doi.org/10.1177/009365096023001001 
Appendix 1. Online Narcissism Personality Scale

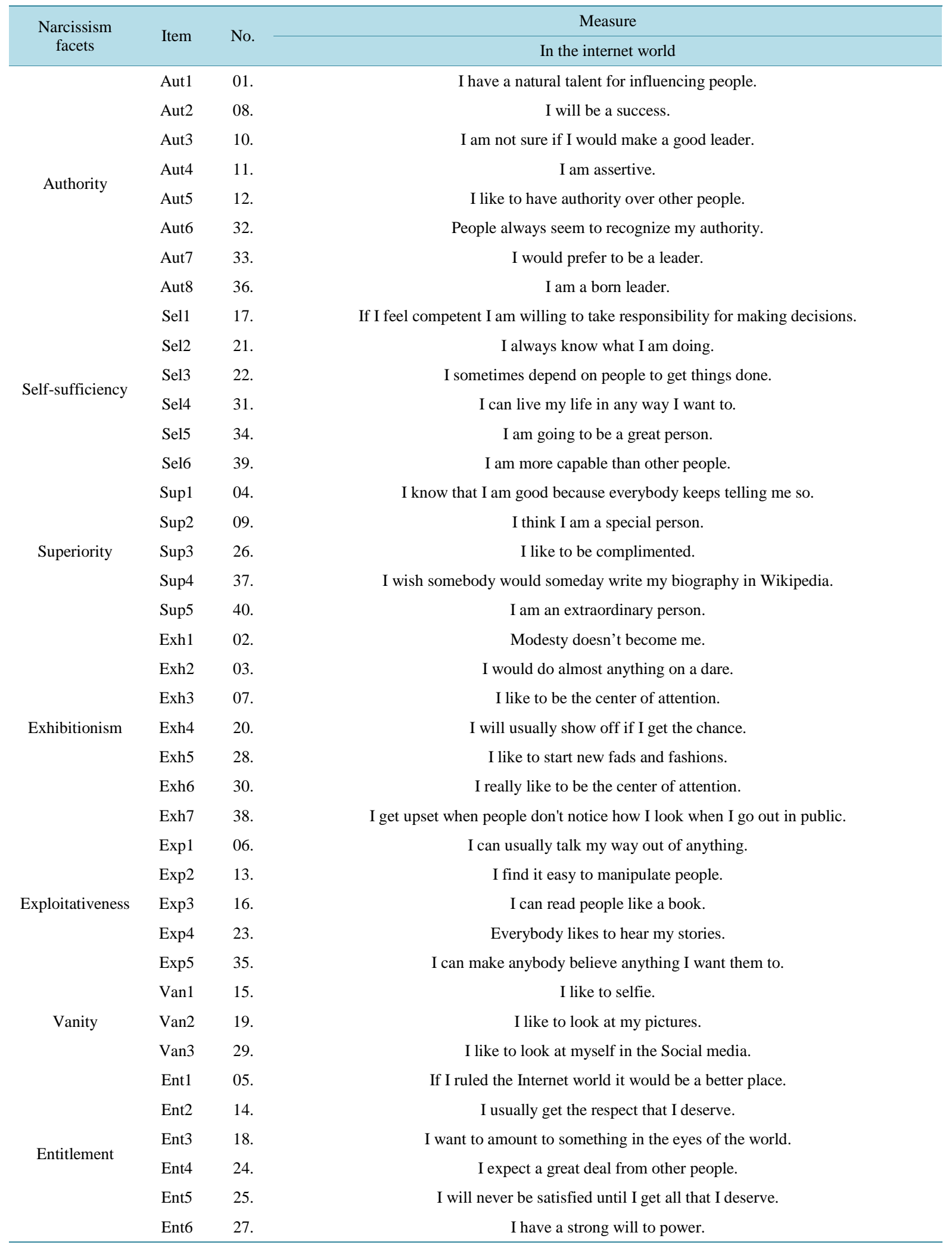

